\title{
Scheduling of undergraduate thesis examination: a case study in Industrial Engineering Department of Universitas Sebelas Maret
}

\author{
Cucuk Nur Rosyidi ${ }^{1}\left[\right.$. Endah Budiningsih ${ }^{1} \cdot$ Wakhid Ahmad Jauhari $^{1}$
}

Received: 11 February 2019 / Accepted: 9 September 2019 / Published online: 20 September 2019

(c) The Author(s) 2019

\begin{abstract}
Undergraduate thesis examination in Industrial Engineering Department of Universitas Sebelas Maret conducted through two stages, namely intermediate and final examination. Currently, the scheduling process of such examinations is done by the undergraduate thesis coordinator manually without certain systematic method or approach. In this paper, we develop an optimization model for the examinations scheduling considering several factors, namely the number of lecturers that must attend the examinations, the availability of rooms for examinations, the availability of each lecturer, and the assignment distributions. The model uses integer programming approach. Two performance criteria are used in the model, namely the difference between the number of each lecturer's assignment with the average number of lecturer assignments and the number of penalties from the assignment of lecturers on certain time slot. The developed model is able to solve the scheduling problem more efficiently than manual scheduling done by thesis coordinator. The optimal solutions from the optimization model show a total difference in the assignment of lecturer with an average of 29.6 and a penalty of 0 .
\end{abstract}

Keywords Scheduling $\cdot$ Timetabling $\cdot$ Integer programming $\cdot$ Invigilator assignment

\section{Introduction}

Timetabling problems have been applied in different domains such as employee allotment, transport systems, educational organizations, sport activities, and industrial applications (Yue et al. 2017). Education timetabling is one of the scheduling problems with a series of activities in the form of courses, subjects, or examinations in a number of limited space involving teachers or lecturers, administrative staffs, and students within a certain period of time. Education timetabling can be defined as scheduling subjects at school, scheduling courses at university, and examination scheduling that is differentiated based on the type of activity, the type of institution involved, and influence of existing constraints (Komijan and Koupaei 2015; Hanum et al. 2015). In general, education timetabling is considered as a big problem with many constraints and become complex combinatorial problem as a part of NP-complete subproblem (Carter and Laporte 1996). Timetabling problems involved

Cucuk Nur Rosyidi

cucuk@uns.ac.id

1 Department of Industrial Engineering, Universitas Sebelas Maret, Jalan Ir. Sutami 36 A, Surakarta 57126, Indonesia hard and soft constraints. Hard constraints deal with model constraints that must be satisfied, while soft constraints are the constraints that may be violated, and both constraints may vary among institutions based on their resources and facilities (Hossain et al. 2019).

The research of timetabling was started with a simple sequential approach in the 1960s and then become emerged as constraint-based approaches. Current researches in the examination scheduling are dominated by the meta-heuristic approach and its integration or hybridization with various approaches, including techniques that existed at the beginning of the emergence of research in this field. Local search, multicriteria, and other approaches have been used to solve these scheduling problems such as variable neighborhood search, iterative local search, GRASP, and hyper-heuristic with the purpose to develop a stronger, more efficient, effective and more general approach (Qu et al. 2009). The issue of course and examination scheduling is important since it is carried out by various educational institutions in the world. The process is often difficult to perform and requires long time if done manually. Even this process is difficult to result viable solutions that can satisfy all parties involved (Laporte and Desroches 1984; Carter and Laporte 1996; McCollum et al. 2009). Generally, the course and examination 
scheduling involves several variables, including the subjects tested, time slots, rooms, lecturers, and examination supervisors and invigilators (Reis and Oliveira 1999).

Laporte and Desroches (1984) proposed a two-stage optimization model to solve examination timetabling. In the first stage, initial feasible schedule was generated by considering several hard constraints. Afterward, the improvement in the initial feasible solution was done by considering two costs, namely aversion and proximity costs. Boizumault et al. (1996) developed a constraint logic programming to solve examination timetabling problem at the West Catholic University in Angers France. Daskalaki et al. (2004) have successfully developed a model for scheduling problems at a university using binary integer programming approach. The model produced timetable without courses, lecturers, and classes scheduled together, allowing successive or repetitive scheduling for certain subjects and considered the assignment of lecturers on the existing certain examination. MirHassani (2006) in his research also used integer programming approach in resolving lectures scheduling problems at Shahrood University of Technology, Iran. McCollum et al. (2009) developed an extended deluge algorithm for examination timetabling problem and tested the algorithm performance using a data set from the 2 nd International Timetabling Competition 2007. A research by Sagir and Ozturk (2010) developed a multi-integer mathematical modeling approach and analytic network process (ANP) for examination scheduling problem in the form of lecturer assignment as invigilators on each examination in the Department of Management, Eskisehir Osmangazi University. The model aimed at minimizing the total cost of the examination assignments, by considering the workload and the number of assignments for each lecturer. The model has successfully assigned lecturers on each schedule that prevents every lecturer to attend more than one examination in the same time slot and each examination has the number of invigilators according to their needs, considering lecturers assignments on certain examinations and willingness of lecturers to become invigilators at a certain time slot.

Kahar and Kendall (2010) proposed a constructive heuristic to solve examination timetabling problem at Universiti Malaysia Pahang (UMP). The heuristic was able to produce good quality solutions which claimed to be superior than the solutions produced by the university's current software. Further, Kahar and Kendall (2014) developed two-phase approach in solving the examination timetabling problem at the UMP. First, they scheduled the examinations into time slot and rooms simultaneously and then used the solution from the first phase as input to the invigilators scheduling phase. Komijan and Koupaei (2012) developed a binary model for examination timetabling problem. The model was then applied and tested in the industrial Engineering Department of Islamic Azad University in Firoozkooh,
Iran. Komijan and Koupaei (2015) extended their model by addressing more specific constraints, such as multi-offered courses and research society members, and types of lecturers. Fiarni et al. (2015) developed a method to solve examination timetabling problem using a heuristic method. Woumans et al. (2016) proposed a column generation algorithm by allowing of an examination to be scheduled to include the spreading of examinations for students. The algorithm was then implemented to solve examination timetabling problem at KU Leuven Campus Brussels, Belgium. Hossain et al. (2019) proposed particle swarm optimization with selective search to solve university course scheduling problem. The proposed method showed its superiority against prominent algorithm such as genetic algorithm and harmony search. Leite et al. (2019) proposed a fast simulated annealing method to solve examination timetabling problem in two phases, namely construction phase and optimization phase.

All the research above solved the problems of course and its examination timetabling. Only Fiarni et al. (2015) dealt with thesis examination with no optimal results guarantee due to the use of heuristic method. Thesis examination has different characteristics with course timetabling such as thesis has a serial steps to finish and each step needs different schedules. In this research, we aim to provide a much more efficient method for the coordinator of undergraduate thesis at Industrial Engineering Department of Universitas Sebelas Maret (IE-UNS) in generating thesis schedule which currently made manually. Hence, we develop a multi-objective optimization model to accommodate the objectives of the coordinator. The model in this research was adopted from the model that has been developed by Sagir and Ozturk (2010). The first objective function in this research aims to minimize the total difference between assignments of each lecturer with the average number of the all lecturer assignments. The second objective function is to minimize the penalty resulted from scheduling the thesis examination that coincides with lecturer activities, mainly the courses. Table 1 shows the published literature in timetabling problem and the position of this research.

\section{System description}

Undergraduate Program of Industrial Engineering at Universitas Sebelas Maret has several examination timetabling problems, namely mid-semester examinations (MSE), final semester exams (FSE), and thesis exams (TE). MSE and FSE are conducted on weekdays, and the schedule of both examinations follows the normal course schedule, whereas thesis examinations are carried out through two stages, namely intermediate and final examinations. Currently, the scheduling process is done manually without using certain methods or approaches. The coordinator schedules both intermediate 
Table 1 The published literature of timetabling problem and the position of this research

\begin{tabular}{|c|c|c|c|c|c|c|c|}
\hline \multirow[t]{3}{*}{ Research } & \multicolumn{2}{|c|}{$\begin{array}{l}\text { Objective func- } \\
\text { tion }\end{array}$} & \multicolumn{3}{|c|}{ Timetabling problem } & \multicolumn{2}{|c|}{ Timetabling case } \\
\hline & \multirow[t]{2}{*}{ Single } & \multirow[t]{2}{*}{ Multi } & \multirow[t]{2}{*}{ Course } & \multicolumn{2}{|c|}{ Examination } & \multirow[t]{2}{*}{ University } & \multirow[t]{2}{*}{ Others } \\
\hline & & & & Course & Thesis & & \\
\hline Laporte and Desroches (1984) & $\sqrt{ }$ & & & $\sqrt{ }$ & & $\sqrt{ }$ & \\
\hline Boizumault et al. (1996) & $\sqrt{ }$ & & & $\sqrt{ }$ & & $\sqrt{ }$ & \\
\hline Daskalaki et al. (2004) & $\sqrt{ }$ & & $\sqrt{ }$ & & & $\sqrt{ }$ & \\
\hline MirHassani (2006) & $\sqrt{ }$ & & $\sqrt{ }$ & & & $\sqrt{ }$ & \\
\hline McCollum et al. (2009) & $\sqrt{ }$ & & & $\sqrt{ }$ & & & $\sqrt{ }$ \\
\hline Sagir and Ozturk (2010) & & $\sqrt{ }$ & & $\sqrt{ }$ & & $\sqrt{ }$ & \\
\hline Komijan and Koupaei (2012) & $\sqrt{ }$ & & & $\sqrt{ }$ & & $\sqrt{ }$ & \\
\hline Komijan and Koupaei (2015) & $\sqrt{ }$ & & $\sqrt{ }$ & & & $\sqrt{ }$ & \\
\hline Fiarni et al. (2015) & $\sqrt{ }$ & & & & $\sqrt{ }$ & $\sqrt{ }$ & \\
\hline Woumans et al. (2016) & $\sqrt{ }$ & & & $\sqrt{ }$ & & $\sqrt{ }$ & \\
\hline Leite et al. (2019) & $\sqrt{ }$ & & & $\sqrt{ }$ & & & $\sqrt{ }$ \\
\hline This research & & $\sqrt{ }$ & & & $\sqrt{ }$ & $\sqrt{ }$ & \\
\hline
\end{tabular}

and final examinations for each student one by one. Hence, in this research, we address the TE to help the coordinator in solving the scheduling problems in more efficient way. The undergraduate thesis examination has several features. First, the scheduling process involves a process of scheduling and assigning of lecturers as supervisors and invigilators. Second, the coordinator has to consider several hard constraints: (1) Every intermediate and final examinations must be attended by two supervisors and two invigilators, (2) each lecturer cannot attend two intermediate and final examinations at the same time, (3) the examination room cannot be used by more than one intermediate and final examinations at the same time, and (4) the schedule must consider several lecturer activities such as course lecture, research, and other academic activities. Third, each lecturer has different time availability where the difficulty arises in this case to find a feasible schedule. Finally, the coordinator has to balance the assignments among the lecturers. Those two difficulties were known as soft constraints in the process of timetable scheduling.

In the current practice, the scheduling process is started with the request from thesis coordinator to each of the lecturer about their time availability in the examination process. Afterward, the coordinator will build a schedule for a set of registered student's thesis considering that time availability. The examination is held on the week days with four time slots available on Monday-Thursday and three time slots on Friday. Every thesis seminar and final examinations must be attended by two supervisors and two invigilators. In determining the schedule, there are several factors that must be considered by the coordinator such as the total period of seminar and final examinations which usually take place for 2 until 3 weeks, the schedule of lecturer's activities including research, conferences, and other official activities, and the distribution of thesis intermediate and final examinations that should be balanced among the lecturers.

\section{Model development}

The model developed in this paper is based on the research of Sagir and Ozturk (2010) using binary integer programming model. Two models are developed in this research: thesis intermediate examination scheduling and final examination scheduling.

The following notations are used in the model:

$i=$ the number of supervisors and invigilators for the thesis, $i=1 \ldots I$.

$j=$ the number of sessions at a certain time slot, $j=1 \ldots J$.

$k=$ the number of time slot during one scheduling period, $k=1 \ldots K$.

$U=$ a set of time slots which is not available for each lecturer

$V=$ a set of examinations that has been assigned to each lecturer

$y_{i k}=$ the amount of penalty given to lecturer $i$ at time slot $k$

$m_{i k}=$ time availability of lecturer $i$ at time slot $k$

$m_{i k}\left\{\begin{array}{l}1, \text { if lecturer } i \text { is not available for time slot } k \\ 0, \text { otherwise }\end{array}\right.$

$p_{i j}=$ assignment of lecturer $i$ on the examination session $j$ as a supervisor or invigilator.

$p_{i j}\left\{\begin{array}{l}1, \text { if lecturer } i \text { is assigned as a supervisor or invigilator for the exam session } j \\ 0, \text { otherwise }\end{array}\right.$ 
$x_{i j k}=$ assignment of lecturer $i$ for final examination session $j$ at time slot $k$ minimum objective function value of Eq. (1) is 24 with the maximum value of 56, whereas minimizing Eq. (2) will

$x_{i j k}\left\{\begin{array}{l}1, \text { if lecturer } i \text { is assigned as a supervisor or invigilator for the exam session jat time slot } k \\ 0, \text { otherwise }\end{array}\right.$

$z_{j k}=$ final examination session $j$ scheduled at time slot $k$

$z_{j k} \begin{cases}1, & \text { if } \sum_{i \in I} x_{i j k}=4 \quad \forall j \in J, k \in K \\ 0, & \text { if } \sum_{i \in I} x_{i j k} \neq 4 \quad \forall j \in J, k \in K\end{cases}$

\section{Thesis examinations scheduling model}

\section{The objective function}

This model has a multi-objective structure because it has two objective functions. The first objective function is to minimize the difference between lecturer assignments with the average number of total lecturer assignments. The second objective function is to minimize the total penalties due to the scheduling of the final examinations in the same time with certain class lecturing. Equation (11) is the mathematical model for the first objective function (F1), while Eq. (12) is the second objective function $(\mathrm{F} 2)$.

$$
\begin{aligned}
F 1 & =\sum_{i \in I}\left[\sum_{j \in J} \sum_{k \in K} x_{i j k}-\frac{4 J}{I}\right] \\
F 2 & =\sum_{i \in I} \sum_{k \in K} \sum_{j \in J} x_{i j k} y_{i k}
\end{aligned}
$$

The two objective functions are solved simultaneously. Thus, to combine both objective functions, the transformation function is needed (Marler and Arora 2004). It is called the upper-lower bound approach, where minimum value and maximum value of each objective function are determined first, and then, those values are put into the following equation.

$F_{i}^{\operatorname{trans}}=\frac{F_{i}(x)-F_{i}^{\circ}}{F_{i}^{\max }-F_{i}^{\circ}}$

In Eq. (3), $F_{i}(x)$ denotes the current objective function, while $F_{i}^{\max }, F_{i}^{\circ}$, and $F_{i}^{\text {trans }}$ denote the maximum value, the minimum value, and transformed value of the objective functions, respectively.

The first objective function is the mini-sum function adopted from the model of Hanum et al. (2015) to balance the lecturer assignments. From the execution of our model using Eqs. (1) and (2) separately, we found the result in the value of 94 while maximizing the same equation will result in the value of 343 . So, the exact transformation form of Eq. (3) will appear as follows:

$$
\begin{gathered}
\text { Minimize } \frac{\sum_{i \in I}\left[\sum_{j \in J} \sum_{k \in K} x_{i j k}-\frac{4 J}{I}\right]-24}{32} \\
+\frac{\sum_{i \in I} \sum_{k \in K} \sum_{j \in J} x_{i j k} y_{i k}-94}{249}
\end{gathered}
$$

\section{Constraints set}

The constraints of the model are as follows:

1. Each thesis intermediate and final examinations session needs four lecturers.

$$
\sum_{i \in I} \sum_{k \in K} x_{i j k}=4 \quad \forall j \in J
$$

2. The constraint used to limit each particular lecturer only to be assigned for a particular examination session at one time slot only. Hence, every lecturer has the same opportunity not to be assigned at a particular session on one of the time slots or each lecturer can be assigned at a particular session on exactly one of the time slots.

$\sum_{k \in K} x_{i j k} \leq 1 \quad \forall j \in J, i \in I$

Table 2 List of participants for intermediate and final examinations

\begin{tabular}{lllll}
\hline No. & Notation & $\begin{array}{l}\text { Participant } \\
\text { initial }\end{array}$ & Thesis code & $\begin{array}{l}\text { Intermediate/final exami- } \\
\text { nation }\end{array}$ \\
\hline 1 & $j_{1}$ & DP & $\mathrm{T}_{1}$ & Final examination \\
2 & $j_{2}$ & GK & $\mathrm{T}_{2}$ & Final examination \\
3 & $j_{3}$ & MS & $\mathrm{T}_{3}$ & Final examination \\
4 & $j_{4}$ & ZIM & $\mathrm{T}_{4}$ & Final examination \\
5 & $j_{5}$ & ARK & $\mathrm{T}_{5}$ & Intermediate examination \\
6 & $j_{6}$ & EYN & $\mathrm{T}_{6}$ & Intermediate examination \\
7 & $j_{7}$ & VA & $\mathrm{T}_{7}$ & Intermediate examination \\
8 & $j_{8}$ & AAP & $\mathrm{T}_{8}$ & Intermediate examination \\
9 & $j_{9}$ & GAG & $\mathrm{T}_{9}$ & Intermediate examination \\
10 & $j_{10}$ & DN & $\mathrm{T}_{10}$ & Intermediate examination \\
11 & $j_{11}$ & HK & $\mathrm{T}_{11}$ & Intermediate examination \\
12 & $j_{12}$ & RDS & $\mathrm{T}_{12}$ & Intermediate examination \\
13 & $j_{13}$ & YS & $\mathrm{T}_{13}$ & Intermediate examination \\
14 & $j_{14}$ & RH & $\mathrm{T}_{14}$ & Intermediate examination \\
\hline
\end{tabular}


3. Constraint used to limit each lecturer only be assigned to one particular session at each time slot. Hence, every lecturer cannot be assigned to more than one session at each time slot.

$$
\sum_{j \in J} x_{i j k} \leq 1 \quad \forall k \in K, i \in I
$$

4. Equation (8) is used to ensure that the supervisors and invigilators are the same for one undergraduate thesis and will be scheduled according to the intermediate examination session.

$$
\sum_{k \in K} x_{i j k}=p_{i j} \quad \exists(i, j) \in V
$$

5. Constraint in Eq. (9) is used to ensure that the supervisors or invigilators are not scheduled to certain examination session on the time slot where the lecturer has another agenda, such as research, course, or other activities.
Table 3 List of lecturers assigned as supervisors and

\begin{tabular}{|c|c|c|c|c|c|}
\hline No. & Notation & Lecturer initial & Assignment & Student initial & Intermediate/final examination \\
\hline 1. & $i_{1}$ & EL & $\begin{array}{l}\text { Supervisor } \\
\text { Supervisor } \\
\text { Supervisor } \\
\text { Supervisor } \\
\text { Supervisor }\end{array}$ & $\begin{array}{l}\text { ZIM } \\
\text { ARK } \\
\text { EYN } \\
\text { DN } \\
\text { RH }\end{array}$ & $\begin{array}{l}\text { Final examination } \\
\text { Intermediate examination } \\
\text { Intermediate examination } \\
\text { Intermediate examination } \\
\text { Intermediate examination }\end{array}$ \\
\hline 2. & $i_{2}$ & $\mathrm{RZ}$ & Invigilator & ZIM & Final examination \\
\hline 3. & $i_{3}$ & IP & $\begin{array}{l}\text { Invigilator } \\
\text { Supervisor } \\
\text { Supervisor }\end{array}$ & $\begin{array}{l}\text { DP } \\
\text { VA } \\
\text { AAP }\end{array}$ & $\begin{array}{l}\text { Final examination } \\
\text { Intermediate examination } \\
\text { Intermediate examination }\end{array}$ \\
\hline 4. & $i_{4}$ & RDA & $\begin{array}{l}\text { Supervisor } \\
\text { Supervisor } \\
\text { Supervisor }\end{array}$ & $\begin{array}{l}\text { DP } \\
\text { GK } \\
\text { VA }\end{array}$ & $\begin{array}{l}\text { Final examination } \\
\text { Final examination } \\
\text { Intermediate examination }\end{array}$ \\
\hline 5. & $i_{5}$ & $\mathrm{CNR}$ & Supervisor & MS & Final examination \\
\hline 6. & $i_{6}$ & LH & $\begin{array}{l}\text { Invigilator } \\
\text { Invigilator } \\
\text { Supervisor }\end{array}$ & $\begin{array}{l}\text { DP } \\
\text { GK } \\
\text { GAG }\end{array}$ & $\begin{array}{l}\text { Final examination } \\
\text { Final examination } \\
\text { Intermediate examination }\end{array}$ \\
\hline 7. & $i_{7}$ & $\mathrm{BS}$ & $\begin{array}{l}\text { Supervisor } \\
\text { Supervisor }\end{array}$ & $\begin{array}{l}\text { DP } \\
\text { GK }\end{array}$ & $\begin{array}{l}\text { Final examination } \\
\text { Final examination }\end{array}$ \\
\hline 8. & $i_{8}$ & PWL & $\begin{array}{l}\text { Invigilator } \\
\text { Invigilator } \\
\text { Supervisor }\end{array}$ & $\begin{array}{l}\text { GK } \\
\text { MS } \\
\text { RDS }\end{array}$ & $\begin{array}{l}\text { Final examination } \\
\text { Final examination } \\
\text { Final examination }\end{array}$ \\
\hline 9. & $i_{9}$ & WAJ & $\begin{array}{l}\text { Supervisor } \\
\text { Supervisor }\end{array}$ & $\begin{array}{l}\text { MS } \\
\text { RDS }\end{array}$ & $\begin{array}{l}\text { Final examination } \\
\text { Final examination }\end{array}$ \\
\hline 10. & $i_{10}$ & MH & Invigilator & MS & Final examination \\
\hline 11. & $i_{11}$ & FF & Invigilator & ZIM & Final examination \\
\hline 12. & $i_{12}$ & WS & Supervisor & ZIM & Final examination \\
\hline 13. & $i_{13}$ & IWS & $\begin{array}{l}\text { Supervisor } \\
\text { Supervisor } \\
\text { Supervisor } \\
\text { Supervisor } \\
\text { Supervisor }\end{array}$ & $\begin{array}{l}\text { ARK } \\
\text { EYN } \\
\text { DN } \\
\text { HK } \\
\text { RH }\end{array}$ & $\begin{array}{l}\text { Intermediate examination } \\
\text { Intermediate examination } \\
\text { Intermediate examination } \\
\text { Intermediate examination } \\
\text { Intermediate examination }\end{array}$ \\
\hline 14. & $i_{14}$ & SS & $\begin{array}{l}\text { Supervisor } \\
\text { Supervisor }\end{array}$ & $\begin{array}{l}\text { AAP } \\
\text { GAG }\end{array}$ & $\begin{array}{l}\text { Intermediate examination } \\
\text { Intermediate examination }\end{array}$ \\
\hline 15. & $i_{15}$ & YP & Supervisor & HK & Intermediate examination \\
\hline 16. & $i_{16}$ & RWD & Supervisor & YS & Intermediate examination \\
\hline 17. & $i_{17}$ & IRF & Supervisor & YS & Intermediate examination \\
\hline 18. & $i_{18}$ & EP & - & - & - \\
\hline 19. & $i_{19}$ & YA & - & - & - \\
\hline 20. & $i_{20}$ & TR & - & - & - \\
\hline
\end{tabular}
invigilators 
Table 4 Time slots of intermediate and final examinations

\begin{tabular}{|c|c|c|c|c|c|c|c|}
\hline Date & Time & Slot & Notation & Date & Time & Slot & Notation \\
\hline \multirow[t]{4}{*}{ Wednesday, October 18, 2017} & $08.00-09.45$ & 1 & $k_{1}$ & \multirow[t]{4}{*}{ Thursday, October 26, 2017} & $08.00-09.45$ & 24 & $k_{24}$ \\
\hline & $10.00-11.45$ & 2 & $k_{2}$ & & $10.00-11.45$ & 25 & $k_{25}$ \\
\hline & $13.00-14.45$ & 3 & $k_{3}$ & & $13.00-14.45$ & 26 & $k_{26}$ \\
\hline & $15.30-16.45$ & 4 & $k_{4}$ & & $15.30-16.45$ & 27 & $k_{27}$ \\
\hline \multirow[t]{4}{*}{ Thursday, October 19, 2017} & $08.00-09.45$ & 5 & $k_{5}$ & \multirow[t]{3}{*}{ Friday, October 27, 2017} & $08.30-10.30$ & 28 & $k_{28}$ \\
\hline & $10.00-11.45$ & 6 & $k_{6}$ & & $13.00-14.45$ & 29 & $k_{29}$ \\
\hline & $13.00-14.45$ & 7 & $k_{7}$ & & $15.30-16.45$ & 30 & $k_{30}$ \\
\hline & $15.30-16.45$ & 8 & $k_{8}$ & \multirow[t]{4}{*}{ Monday, October 30, 2017} & $08.00-09.45$ & 31 & $k_{31}$ \\
\hline \multirow[t]{3}{*}{ Friday, October 20, 2017} & $08.30-10.30$ & 9 & $k_{9}$ & & $10.00-11.45$ & 32 & $k_{32}$ \\
\hline & $13.00-14.45$ & 10 & $k_{10}$ & & $13.00-14.45$ & 33 & $k_{33}$ \\
\hline & $15.30-16.45$ & 11 & $k_{11}$ & & $15.30-16.45$ & 34 & $k_{34}$ \\
\hline \multirow[t]{4}{*}{ Monday, October 23, 2017} & $08.00-09.45$ & 12 & $k_{12}$ & \multirow[t]{4}{*}{ Tuesday, October 31, 2017} & $08.00-09.45$ & 35 & $k_{35}$ \\
\hline & $10.00-11.45$ & 13 & $k_{13}$ & & $10.00-11.45$ & 36 & $k_{36}$ \\
\hline & $13.00-14.45$ & 14 & $k_{14}$ & & $13.00-14.45$ & 37 & $k_{37}$ \\
\hline & $15.30-16.45$ & 15 & $k_{15}$ & & $15.30-16.45$ & 38 & $k_{38}$ \\
\hline \multirow[t]{4}{*}{ Tuesday, October 24, 2017} & $08.00-09.45$ & 16 & $k_{16}$ & \multirow[t]{8}{*}{ Wednesday, November 1, 2017} & $08.00-09.45$ & 39 & $k_{39}$ \\
\hline & $10.00-11.45$ & 17 & $k_{17}$ & & $10.00-11.45$ & 40 & $k_{40}$ \\
\hline & $13.00-14.45$ & 18 & $k_{18}$ & & $13.00-14.45$ & 41 & $k_{41}$ \\
\hline & $15.30-16.45$ & 19 & $k_{19}$ & & $15.30-16.45$ & 42 & $k_{42}$ \\
\hline \multirow[t]{4}{*}{ Wednesday, October 25, 2017} & $08.00-09.45$ & 20 & $k_{20}$ & & & & \\
\hline & $10.00-11.45$ & 21 & $k_{21}$ & & & & \\
\hline & $13.00-14.45$ & 22 & $k_{22}$ & & & & \\
\hline & $15.30-16.45$ & 23 & $k_{23}$ & & & & \\
\hline
\end{tabular}

Table 5 Penalty of each time slot

\begin{tabular}{lllll}
\hline No. & \multicolumn{2}{l}{ Time slot } & & \\
\cline { 2 - 5 } & $08.00-09.45$ & $10.00-11.45$ & $13.00-14.45$ & $15.30-16.45$ \\
\hline 1 & 6 & 1 & 3 & 10 \\
2 & 10 & 1 & 3 & 6 \\
3 & 1 & 3 & 6 & 10 \\
4 & 10 & 1 & 3 & 6 \\
5 & 10 & 1 & 3 & 10 \\
Average & 7.4 & 1.4 & 3.6 & 8.4 \\
\hline
\end{tabular}

$$
\sum_{j \in J} x_{i j k}=m_{i k}-1 \quad \exists(i, t) \in U
$$

6. Constraint in Eq. (10) is used to ensure that after the previous five constraints have been fulfilled and each examination has appropriate two supervisors and two invigilators, then the examination must be scheduled at the same time slot.

$$
\sum_{k \in K} z_{j k}=1 \quad \forall j \in J
$$

7. Equations (11)-(13) are needed to limit the assignments of the rooms, in which each time slot is not scheduled more than the examination room available at a time. Equation (11) is used when there are two examination rooms available at a certain time slot. Equation (12) is used only one examination room is available at a certain time slot, while Eq. (13) is used when there is no room available for examinations because it is being used for other activities.

$\sum_{j \in J} z_{j k} \leq 2 \quad \forall k \in K$

$\sum_{j \in J} z_{j k} \leq 1$

$$
\sum_{j \in J} z_{j k} \leq 0
$$

\section{Results and discussion}

The model developed in this paper is then used to solve the intermediate and final examinations scheduling in IE-UNS in the period of October 2017. In that period, there were four thesis final examinations and ten thesis intermediate examinations should be scheduled. The list of participants for thesis examinations session is given in Table 2 . 
Table 6 Lecturers' teaching schedule during thesis examination period

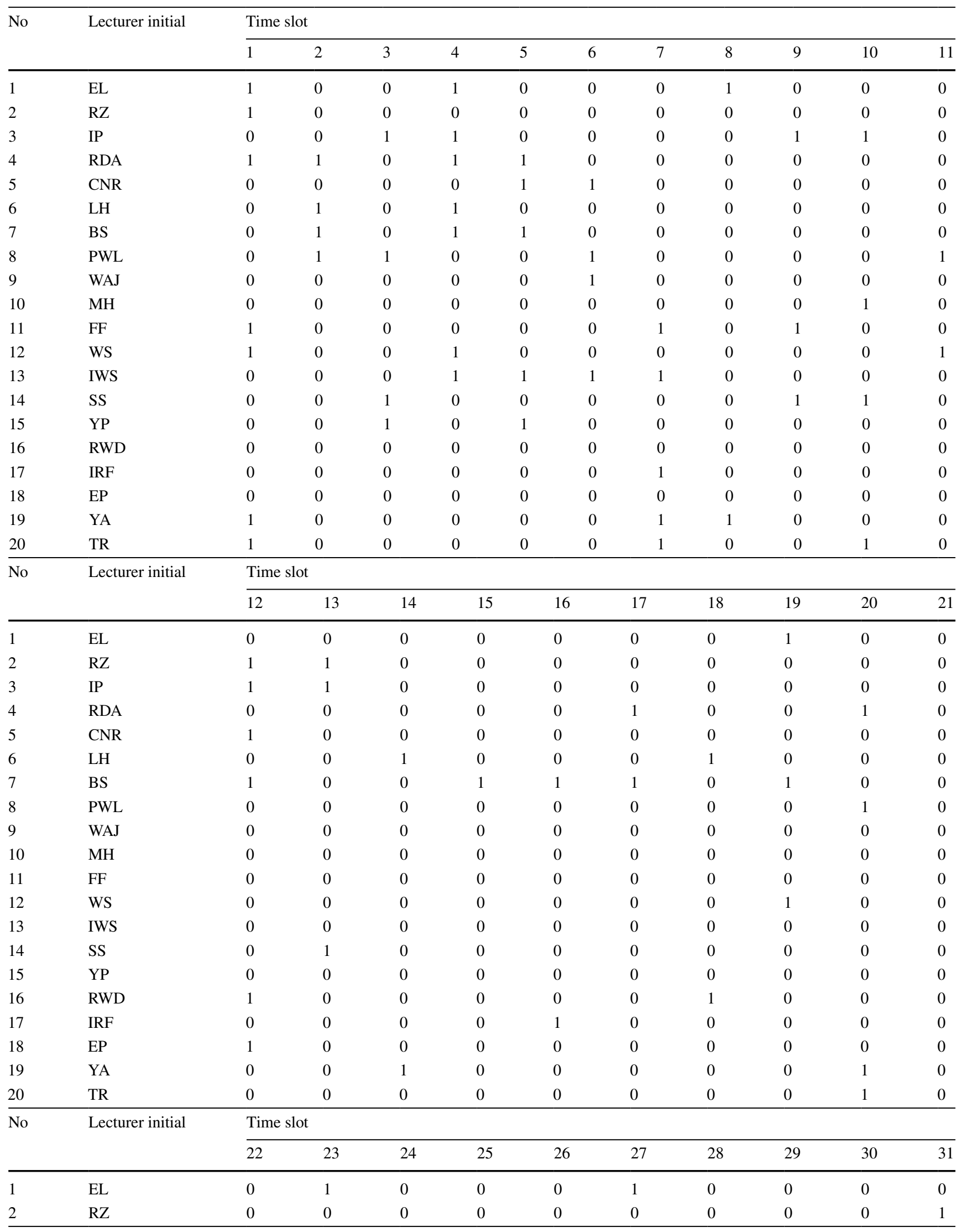


Table 6 (continued)

\begin{tabular}{|c|c|c|c|c|c|c|c|c|c|c|c|c|c|}
\hline \multirow[t]{2}{*}{ No } & \multirow[t]{2}{*}{ Lecturer initial } & \multicolumn{12}{|c|}{ Time slot } \\
\hline & & 22 & 23 & 24 & & 25 & & 26 & 27 & 28 & 29 & 30 & 31 \\
\hline 3 & IP & 1 & 0 & 0 & & 0 & & 1 & 0 & 1 & 0 & 0 & 1 \\
\hline 4 & RDA & 0 & 0 & 1 & & 0 & & 0 & 0 & 0 & 0 & 0 & 0 \\
\hline 5 & CNR & 0 & 0 & 1 & & 1 & & 0 & 0 & 0 & 0 & 0 & 1 \\
\hline 6 & LH & 0 & 0 & 0 & & 0 & & 0 & 0 & 0 & 0 & 0 & 0 \\
\hline 7 & BS & 0 & 0 & 1 & & 0 & & 0 & 0 & 0 & 0 & 0 & 1 \\
\hline 8 & PWL & 0 & 0 & 0 & & 1 & & 0 & 0 & 0 & 0 & 1 & 0 \\
\hline 9 & WAJ & 0 & 0 & 0 & & 1 & & 0 & 0 & 0 & 0 & 0 & 0 \\
\hline 10 & MH & 0 & 0 & 0 & & 0 & & 0 & 0 & 0 & 1 & 0 & 0 \\
\hline 11 & $\mathrm{FF}$ & 0 & 0 & 0 & & 0 & & 1 & 0 & 1 & 0 & 0 & 0 \\
\hline 12 & WS & 0 & 1 & 0 & & 0 & & 0 & 0 & 0 & 0 & 1 & 0 \\
\hline 13 & IWS & 0 & 1 & 1 & & 1 & & 1 & 0 & 0 & 0 & 0 & 0 \\
\hline 14 & SS & 1 & 0 & 0 & & 0 & & 0 & 0 & 1 & 1 & 0 & 0 \\
\hline 15 & YP & 1 & 0 & 1 & & 0 & & 0 & 0 & 0 & 0 & 0 & 0 \\
\hline 16 & RWD & 0 & 0 & 0 & & 0 & & 0 & 0 & 0 & 0 & 0 & 1 \\
\hline 17 & IRF & 0 & 0 & 0 & & 0 & & 1 & 0 & 0 & 0 & 0 & 0 \\
\hline 18 & $\mathrm{EP}$ & 0 & 0 & 0 & & 0 & & 0 & 0 & 0 & 0 & 0 & 1 \\
\hline 19 & YA & 0 & 0 & 0 & & 0 & & 1 & 1 & 0 & 0 & 0 & 0 \\
\hline 20 & $\mathrm{TR}$ & 0 & 0 & 0 & & 0 & & 1 & 0 & 0 & 1 & 0 & 0 \\
\hline \multirow[t]{2}{*}{ No } & Lecturer initial & \multicolumn{12}{|c|}{ Time slot } \\
\hline & & 32 & 33 & 34 & 35 & & 36 & 37 & 38 & 39 & 40 & 41 & 42 \\
\hline 1 & EL & 0 & 0 & 0 & 0 & & 0 & 0 & 1 & 0 & 0 & 0 & 1 \\
\hline 2 & $\mathrm{RZ}$ & 1 & 0 & 0 & 0 & & 0 & 0 & 0 & 0 & 0 & 0 & 0 \\
\hline 3 & IP & 1 & 0 & 0 & 0 & & 0 & 0 & 0 & 0 & 0 & 0 & 0 \\
\hline 4 & RDA & 0 & 0 & 0 & 0 & & 1 & 0 & 0 & 1 & 0 & 0 & 0 \\
\hline 5 & CNR & 0 & 0 & 0 & 0 & & 0 & 0 & 0 & 0 & 0 & 0 & 0 \\
\hline 6 & LH & 0 & 1 & 0 & 0 & & 0 & 1 & 0 & 0 & 0 & 0 & 0 \\
\hline 7 & BS & 0 & 0 & 1 & 1 & & 1 & 0 & 1 & 0 & 0 & 0 & 0 \\
\hline 8 & PWL & 0 & 0 & 0 & 0 & & 0 & 0 & 0 & 0 & 0 & 1 & 0 \\
\hline 9 & WAJ & 0 & 0 & 0 & 0 & & 0 & 0 & 0 & 0 & 0 & 0 & 0 \\
\hline 10 & $\mathrm{MH}$ & 0 & 0 & 0 & 0 & & 0 & 0 & 0 & 0 & 0 & 0 & 0 \\
\hline 11 & $\mathrm{FF}$ & 0 & 0 & 0 & 0 & & 0 & 0 & 0 & 0 & 0 & 0 & 0 \\
\hline 12 & WS & 0 & 0 & 0 & 0 & & 0 & 0 & 1 & 0 & 0 & 0 & 1 \\
\hline 13 & IWS & 0 & 0 & 0 & 0 & & 0 & 0 & 0 & 0 & 0 & 0 & 1 \\
\hline 14 & SS & 1 & 0 & 0 & 0 & & 0 & 0 & 0 & 0 & 0 & 1 & 0 \\
\hline 15 & YP & 0 & 0 & 0 & 0 & & 0 & 0 & 0 & 0 & 0 & 1 & 0 \\
\hline 16 & RWD & 0 & 0 & 0 & 0 & & 0 & 1 & 0 & 0 & 0 & 0 & 0 \\
\hline 17 & IRF & 0 & 0 & 0 & 1 & & 0 & 0 & 0 & 0 & 0 & 0 & 0 \\
\hline 18 & EP & 0 & 0 & 0 & 0 & & 0 & 0 & 0 & 0 & 0 & 0 & 0 \\
\hline 19 & YA & 0 & 1 & 0 & 0 & & 0 & 0 & 0 & 1 & 0 & 0 & 0 \\
\hline 20 & TR & 0 & 0 & 0 & 0 & & 0 & 0 & 0 & 1 & 0 & 0 & 0 \\
\hline
\end{tabular}

In the period of October 2017, there were 20 lecturers available as supervisors and invigilators. The list of lecturers assigned as supervisor and invigilators for thesis examinations session for the October 2017 as well as students advised by lecturers is shown in Table 3 .
The examinations are held from Monday to Thursday with four time slots: 08.00-09:45, 10:00-11:45, 13.00-14.45, and 15.00-16:45, whereas on Friday, there are only three time slots: $08.30-10: 30,13.00-14.30$, and at 15.30-17.00. The detail of all slots with their respective notations is listed in Table 4. 
Table 7 Optimization results of final examination scheduling

\begin{tabular}{lllllll}
\hline No. & Student initial & Thesis code & Date & Time slot & Supervisors & Invigilators \\
\hline 1. & DP & $\mathrm{T}_{1}$ & Thursday, October 19, 2017 & $15.00-16.45$ & BS and RDA & IP and LH \\
2. & GK & $\mathrm{T}_{2}$ & Friday, October 27, 2017 & $13.00-14.45$ & RDA and BS & LH and PWL \\
3. & MS & $\mathrm{T}_{3}$ & Wednesday, November 1, 2017 & $10.00-11.45$ & WAJ and CNR & MH and PWL \\
4. & ZIM & $\mathrm{T}_{4}$ & Wednesday, November 1, 2017 & $10.00-11.45$ & EL and WS & FF and RZ \\
\hline
\end{tabular}

Table 8 Thesis seminar scheduling optimization result

\begin{tabular}{lllllll}
\hline No. & Student initial & Thesis code & Date & Time slot & Supervisor & Invigilator \\
\hline 1. & ARK & $\mathrm{T}_{5}$ & Wednesday, October 25, 2017 & $13.00-14.45$ & IWS and EL & BS and WAJ \\
2. & EYN & $\mathrm{T}_{6}$ & Wednesday, October 18, 2017 & $13.00-14.45$ & IWS and EL & RDA and RWD \\
3. & WA & $\mathrm{T}_{7}$ & Thursday, October 19, 2017 & $13.00-14.45$ & IP and RDA & RZ and YP \\
4. & AAP & $\mathrm{T}_{8}$ & Wednesday, November 1, 2017 & $08.00-09.45$ & IP and SS & CNR and BS \\
5. & GAG & $\mathrm{T}_{9}$ & Wednesday, October 18, 2017 & $10.00-11.45$ & LH and SS & BS and WAJ \\
6. & DN & $\mathrm{T}_{10}$ & Monday, October 31, 2017 & $10.00-11.45$ & IWS and EL & IRF and TR \\
7. & HK & $\mathrm{T}_{11}$ & Friday, October 20, 2017 & $13.00-14.45$ & IWS and YP & RDA and YN \\
8. & RDS & $\mathrm{T}_{12}$ & Thursday, October 19, 2017 & $08.00-09.45$ & WAJ and PWL & RZ and IP \\
9. & YS & $\mathrm{T}_{13}$ & Friday, October 20, 2017 & $13.00-14.45$ & RWD and IRF & RZ and BS \\
10. & RH & $\mathrm{T}_{14}$ & Tuesday, October 24, 2017 & $13.00-14.45$ & IWS and EL & RDA and YA \\
\hline
\end{tabular}

Table 9 Number of assignments for each lecturer

\begin{tabular}{lllll}
\hline No. & Lecturer & \multicolumn{2}{l}{ Number of examinations } & Total \\
\cline { 3 - 5 } & & Intermediate & Final & \\
\hline 1. & EL & 4 & 1 & 5 \\
2. & RZ & 3 & 1 & 4 \\
3. & IP & 3 & 1 & 4 \\
4. & RDA & 4 & 2 & 6 \\
5. & CNR & 1 & 1 & 2 \\
6. & LH. & 1 & 2 & 3 \\
7. & BS & 4 & 2 & 6 \\
8. & PWL & 1 & 2 & 3 \\
9. & WAJ & 3 & 1 & 4 \\
10. & MH & 0 & 1 & 1 \\
11. & FF & 0 & 1 & 1 \\
12. & WS & 0 & 1 & 1 \\
13. & IWS & 5 & 0 & 5 \\
14. & SS & 2 & 0 & 2 \\
15. & YP & 2 & 0 & 2 \\
16. & RWD & 2 & 0 & 2 \\
17. & IRF & 2 & 0 & 2 \\
18. & EP & 0 & 0 & 0 \\
19. & YA & 2 & 0 & 2 \\
20. & TR & 1 & 0 & 1 \\
\hline
\end{tabular}

Table 10 Comparison of optimization results and manual scheduling

\begin{tabular}{|c|c|c|c|c|c|}
\hline \multirow[t]{2}{*}{ No. } & \multirow[t]{2}{*}{ Lecturer } & \multicolumn{2}{|c|}{ Optimization model } & \multicolumn{2}{|c|}{ Manual scheduling } \\
\hline & & $\begin{array}{l}\text { Total } \\
\text { assign- } \\
\text { ment }\end{array}$ & $\begin{array}{l}\text { Difference } \\
\text { average }\end{array}$ & $\begin{array}{l}\text { Total } \\
\text { assign- } \\
\text { ment }\end{array}$ & $\begin{array}{l}\text { Differ- } \\
\text { ence } \\
\text { average }\end{array}$ \\
\hline 1. & EL & 5 & 2.2 & 5 & 2.2 \\
\hline 2. & $\mathrm{RZ}$ & 4 & 1.2 & 2 & 0.8 \\
\hline 3. & IP & 4 & 1.2 & 4 & 1.2 \\
\hline 4. & RDA & 6 & 3.2 & 4 & 1.2 \\
\hline 5. & CNR & 2 & 0.8 & 3 & 0.2 \\
\hline 6. & LH. & 3 & 0.2 & 3 & 0.2 \\
\hline 7. & $\mathrm{BS}$ & 6 & 3.2 & 3 & 0.2 \\
\hline 8. & PWL & 3 & 0.2 & 3 & 0.2 \\
\hline 9. & WAJ & 4 & 1.2 & 3 & 0.2 \\
\hline 10. & MH & 1 & 1.8 & 2 & 0.8 \\
\hline 11. & $\mathrm{FF}$ & 1 & 1.8 & 2 & 0.8 \\
\hline 12. & WS & 1 & 1.8 & 1 & 1.8 \\
\hline 13. & IWS & 5 & 2.2 & 5 & 2.2 \\
\hline 14. & SS & 2 & 0.8 & 3 & 0.2 \\
\hline 15. & YP & 2 & 0.8 & 3 & 0.2 \\
\hline 16. & RWD & 2 & 0.8 & 1 & 1.8 \\
\hline 17. & IRF & 2 & 0.8 & 2 & 0.8 \\
\hline 18. & EP & 0 & 2.8 & 2 & 0.8 \\
\hline 19. & YA & 2 & 0.8 & 2 & 0.8 \\
\hline 20. & TR & 1 & 1.8 & 3 & 0.2 \\
\hline Total & & 56 & 29.6 & 56 & 16.8 \\
\hline
\end{tabular}


Table 11 Comparison of thesis examination scheduling

\begin{tabular}{|c|c|c|c|}
\hline \multirow[t]{2}{*}{ Date } & \multirow[t]{2}{*}{ Time } & \multicolumn{2}{|c|}{$\begin{array}{l}\text { Number of examina- } \\
\text { tion session each time } \\
\text { slot }\end{array}$} \\
\hline & & $\begin{array}{l}\text { Optimi- } \\
\text { zation } \\
\text { model }\end{array}$ & $\begin{array}{l}\text { Manual by } \\
\text { coordinator }\end{array}$ \\
\hline
\end{tabular}

Wednesday, October 18, $2017 \quad 08.00-09.45 \quad 0$

$10.00-11.45 \quad 1$

$13.00-14.45 \quad 1$

$15.30-16.45 \quad 0$

Thursday, October 19, $2017 \quad 08.00-09.45 \quad 1$

$10.00-11.45 \quad 0$

$13.00-14.45 \quad 1$

$15.30-16.45 \quad 1$

Friday, October 20, 2017

$08.30-10.30 \quad 0$

$13.00-14.45 \quad 2$

$15.30-16.45 \quad 0$

Monday, October 23, 2017

$08.00-09.45 \quad 0$

$10.00-11.45 \quad 0$

$13.00-14.45 \quad 0$

$15.30-16.45 \quad 0$

Tuesday, October 24, 2017

$08.00-09.45 \quad 0$

$10.00-11.45 \quad 0$

$13.00-14.45 \quad 1$

$15.30-16.45 \quad 0$

Wednesday, October 25, $2017 \quad 08.00-09.45 \quad 0$

$10.00-11.45 \quad 0$

13.00-14.45 1

$15.30-16.45 \quad 0$

Thursday, October 26, 2017

08.00-09.45 0

10.00-11.45 0

$13.00-14.45 \quad 0$

15.30-16.45 0

Friday, October 27, 2017

08.30-10.30 0

13.00-14.45 1

15.30-16.45 0

08.00-09.45 0

10.00-11.45 0

13.00-14.45 0

15.30-16.45 0

Tuesday, October 31, 2017

08.00-09.45 0

10.00-11.45 1

$13.00-14.45 \quad 0$

15.30-16.45 0

Wednesday, November 1, 2017

$\begin{array}{lll}08.00-09.45 & 1 & 2 \\ 10.00-11.45 & 2 & 0 \\ 13.00-14.45 & 0 & 3 \\ 15.30-16.45 & 0 & 0\end{array}$

Table 12 Objective function

weighting scenarios

\begin{tabular}{lll}
\hline Scenario & F1 & F2 \\
\hline 1 & 1.0 & 0.0 \\
2 & 0.75 & 0.25 \\
3 & 0.25 & 0.75 \\
4 & 0.0 & 1.0 \\
\hline
\end{tabular}

Table 13 Changes in the total number of assignments for each lecturer

\begin{tabular}{llllll}
\hline No. & Lecturer & \multicolumn{2}{l}{ Number of assignments } & \\
\cline { 3 - 6 } & & Scenario 1 & Scenario 2 & Scenario 3 & Scenario 4 \\
\hline 1. & EL & 5 & 5 & 5 & 8 \\
2. & RZ & 4 & 4 & 4 & 6 \\
3. & IP & 4 & 4 & 4 & 3 \\
4. & RDA & 3 & 3 & 5 & 5 \\
5. & CNR & 2 & 4 & 3 & 5 \\
6. & LH. & 4 & 4 & 4 & 4 \\
7. & BS & 4 & 2 & 2 & 3 \\
8. & PWL & 5 & 3 & 3 & 3 \\
9. & WAJ & 2 & 2 & 4 & 2 \\
10. & MH & 1 & 4 & 2 & 1 \\
11. & FF & 2 & 2 & 4 & 1 \\
12. & WS & 3 & 2 & 1 & 1 \\
13. & IWS & 5 & 5 & 5 & 5 \\
14. & SS & 2 & 2 & 2 & 2 \\
15. & YP & 1 & 1 & 2 & 1 \\
16. & RWD & 1 & 2 & 2 & 1 \\
17. & IRF & 2 & 1 & 1 & 1 \\
18. & EP & 2 & 2 & 2 & 0 \\
19. & YA & 2 & 2 & 0 & 1 \\
20. & TR & 2 & 2 & 1 & 3 \\
\hline & & & & & \\
\hline
\end{tabular}

The penalty for each time slot is obtained from the weight that given by the lecturer at each time slot on a scale of 1 to 10 . If a lecturer gives a penalty close to 10 at a certain time slot, then the lecturer will increasingly not want to be scheduled at the time slot. Conversely, if a lecturer gives a penalty weight close to 1 at a certain time slot, then the lecturer increasingly wants to be scheduled for the time slot. Table 5 shows the weight given by five lecturers for each available time slot based on the results of interviews. The five lecturers were selected by accidental sampling or convenience sampling. The values are then averaged and used as the penalty weights for the time slots. Table 6 shows the teaching schedules for each lecturer in the period of intermediate and final examinations. 
Table 14 Changes in assignment from different weighting scenarios

\begin{tabular}{|c|c|c|c|c|c|}
\hline \multirow[t]{2}{*}{ No. } & \multirow[t]{2}{*}{ Lecturer } & \multicolumn{4}{|c|}{ Difference of total assignment with assignment average } \\
\hline & & Scenario 1 & Scenario 2 & Scenario 3 & Scenario 4 \\
\hline 1. & EL & 2.2 & 2.2 & 2.2 & 5.2 \\
\hline 2. & $\mathrm{RZ}$ & 1.2 & 1.2 & 1.2 & 3.2 \\
\hline 3. & IP & 1.2 & 1.2 & 1.2 & 0.2 \\
\hline 4. & RDA & 0.2 & 0.2 & 2.2 & 2.2 \\
\hline 5. & CNR & 0.8 & 1.2 & 0.2 & 2.2 \\
\hline 6. & LH & 1.2 & 1.2 & 1.2 & 1.2 \\
\hline 7. & BS & 1.2 & 0.8 & 0.8 & 0.2 \\
\hline 8. & PWL & 2.2 & 0.2 & 0.2 & 0.2 \\
\hline 9. & WAJ & 0.8 & 0.8 & 1.2 & 0.8 \\
\hline 10. & $\mathrm{MH}$ & 1.8 & 1.2 & 0.8 & 1.8 \\
\hline 11. & $\mathrm{FF}$ & 0.8 & 0.8 & 1.2 & 1.8 \\
\hline 12. & WS & 0.2 & 0.8 & 1.8 & 1.8 \\
\hline 13. & IWS & 2.2 & 2.2 & 2.2 & 2.2 \\
\hline 14. & SS & 0.8 & 0.8 & 0.8 & 0.8 \\
\hline 15. & YP & 1.8 & 1.8 & 0.8 & 1.8 \\
\hline 16. & RWD & 1.8 & 0.8 & 0.8 & 1.8 \\
\hline 17. & IRF & 0.8 & 1.8 & 1.8 & 1.8 \\
\hline 18. & EP & 0.8 & 0.8 & 0.8 & 2.8 \\
\hline 19. & YA & 0.8 & 0.8 & 2.8 & 1.8 \\
\hline 20. & $\mathrm{TR}$ & 0.8 & 0.8 & 1.8 & 0.2 \\
\hline Total & & 23.6 & 21.6 & 26 & 34 \\
\hline
\end{tabular}

\section{Optimization results}

The model was solved using Lingo 15.0. The optimum results of the final examination scheduling problem were obtained after 1764 iterations with a running time of $45 \mathrm{~s}$. The results of optimization for thesis final examination are shown in Table 7. The optimum results of the intermediate exam were obtained after 130,428 iterations with a running time of $6 \mathrm{~min} 15 \mathrm{~s}$ with the objective value of 0.20822 . The optimization results are shown in Table 8 .

The number of assignments for each lecturer and number of examinations for each time slot are shown in Table 9.

\section{Comparison between optimization model and manual scheduling}

The comparison between the optimization results and manual scheduling is shown in Table 10. The table shows that the difference with the average number of lecturer assignments from the optimization results is greater than the scheduling results conducted by the coordinator. In the search for optimal solutions with the developed model, there are parameters that are not in accordance with the actual conditions. This is due to the limited data that can be collected. For example, the time availability of lecturers during the examination period in October 2017 cannot be obtained from the coordinator. In Table 11, we list the comparison of the number of examinations in each time slot. From the table, the results of the optimization schedule show only one schedule from 15.30 to 16.45 on Thursday. This is because during the examination period other than Thursday, the examination room is used for other lecture activities start at 3:00 p.m. This condition has been considered to be one of the constraints in the model. Meanwhile, the timetable developed by the coordinator shows no intermediate and final examinations are scheduled from 15.30 to 16.45 .

\section{Sensitivity analysis}

We perform sensitivity analysis by changing the weight of each objective function on the model developed in this research. The weight represents the priority among the existing objective functions, where the weight can be determined based on the coordinator's preference. The weighting scenarios are shown in Table 12. The changes in the total number of assignments for each lecturer as the results of optimization for each weighting scenario are shown in Table 13.

Table 14 shows that Scenario 3 gives the smallest total assignment difference comparing to the other scenarios.

The comparison of the optimization results for each scenario and initial optimization can be seen in Fig. 1.

From Fig. 1, it can be seen that Scenario 1 and Scenario 2 result in the biggest penalty when the weight for minimizing the penalties is less than 0.5 . Conversely, the total penalty 
Fig. 1 Sensitivity analysis results

\section{Comparison of the Optimization Results}

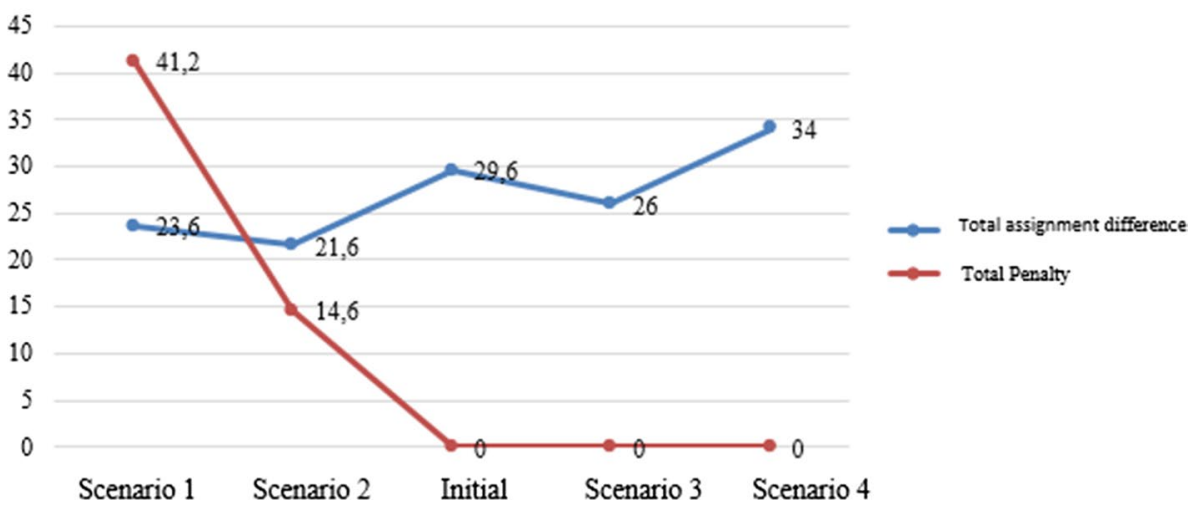

obtained is zero when the weight to minimize the penalty is equal or larger than 0.5 . So, if we want the optimization results with 0 total penalty, we can use Scenario 3 to get scheduling without using the time slot which coincides with the teaching time of a particular lecturer and the total assignment difference is better than the results of the initial optimization, whereas, to get the optimization results with the best total assignment difference, Scenario 2 must be used. However, this scenario produces a penalty that is not equal to zero. So, some schedules require certain lecturers to have the intermediate and final examinations in the same time with the teaching schedules or other activities. The model will reduce the time needed by the coordinator in developing the thesis intermediate and final examinations schedule.

\section{Conclusions}

In this paper, a mathematical model was developed to solve the intermediate and final examinations scheduling problem in Undergraduate Program of Industrial Engineering at Universitas Sebelas Maret, Surakarta, Indonesia. Two performance criteria are used in the model. The first criterion is to minimize the total difference in the assignment of each lecturer with the average of the number of assignments for each lecturer, while the second criterion is to minimize the total penalty resulted from scheduling intermediate or final examinations with teaching schedule of other activities in the same time. The optimal solutions are obtained using the model producing intermediate and final examinations for October 2017 period. The optimization resulted 29.6 in term of the total difference in the assignment of lecturers with its average and 0 penalty. Based on the sensitivity analysis, Scenario 3 produced scheduling with 0 penalty with better total assignment difference than the results in initial optimization, whereas Scenario 2 produced best total difference in assignments, but the penalty is not zero. The model developed in this paper is expected to be used by the coordinator so the scheduling process will become more efficient. Further research is directed to the development of design support system and involving each lecturer in providing their preferences due to the time availability.

Open Access This article is distributed under the terms of the Creative Commons Attribution 4.0 International License (http://creativeco mmons.org/licenses/by/4.0/), which permits unrestricted use, distribution, and reproduction in any medium, provided you give appropriate credit to the original author(s) and the source, provide a link to the Creative Commons license, and indicate if changes were made.

\section{References}

Boizumault P, Delon Y, Peridy L (1996) Constraint logic programming for examination timetabling. J Logic Program 26:217-233

Carter MW, Laporte G (1996) Recent developments in practical examination timetabling. Lecture notes in computer science, vol 1153, Springer, Edinburgh, pp 3-21

Daskalaki S, Birbas T Dan, Housos E (2004) An integer programming formulation for a case study in university timetabling. Eur J Oper Res 153:117-135

Fiarni C, Gunawan AS, Ricky, Maharani H, Kurniawan H (2015) Automated scheduling system for thesis and project presentation using forward chaining method with dynamic allocation resources. Proc Comput Sci 72:209-216

Hanum F, Romliyah MA, Bakhtiar T (2015) Exam invigilator assignment problem: a goal programming approach. Appl Math Sci 9(58):2871-2880

Hossain SI, Akhand MAH, Shuvo MIR, Siddique N, Adeli H (2019) Optimization of university course scheduling problem using particle swarm optimization with selective search. Expert Syst Appl 127:9-24

Kahar MNM, Kendall G (2010) The examination timetabling problem at Universiti Malaysia Pahang: comparison of a constructive heuristic with an existing software solution. Eur J Oper Res 207:557-565

Kahar MNM, Kendall G (2014) Universiti Malaysia Pahang examination timetabling problem: scheduling invigilators. J Oper Res Soc 65:214-226

Komijan AR, Koupaei MN (2012) A new binary model for university examination timetabling: a case study. J Ind Eng Int 8:1-7 
Komijan AR, Koupaei MN (2015) A mathematical model for university course scheduling: a case study. Int J Tech Res Appl Spec Issue 19:20-25

Laporte G, Desroches S (1984) Examination timetabling by computer. Comput Oper Res 11:351-360

Leite N, Melicio F, Rosa AC (2019) A fast simulated annealing algorithm for the examination timetabling problem. Expert Syst Appl 122:137-151

Marler RT, Arora JS (2004) Survey of multi-objective optimization methods for engineering. Struct Multidisc Optim 26:369-395

McCollum B, McMullan PJ, Parkes AJ, Burke EK, Abdullah S (2009) An extended great deluge approach to the examination timetabling problem. In: Proceedings of the 4th multidisciplinary international conference on scheduling: theory and applications (MISTA 2009). Dublin, Ireland, pp 424-434

MirHassani SA (2006) A computational approach to enhancing course timetabling with integer programming. Appl Math Comput $175: 814-822$
Qu R, Burke EK, McCollum B, Merlot LTG, Lee SY (2009) A survey of search methodologies and automated system development for examination timetabling. J Sched 12(1):55-89

Reis LP, Oliveira EA (1999) Constraint logic programming approach to examination scheduling. In: Artificial intelligence and cognitive science conference AICS'99, Cork, Ireland, September

Sagir M, Ozturk ZK (2010) Exam scheduling: mathematical modelling and parameter estimation with analytic network process approach. Math Comput Model 52:930-941

Woumans G, Boeck LD, Belien J, Creemers S (2016) A column generation approach for solving the examination-timetabling problem. Eur J Oper Res 253:178-194

Yue Y, Han J, Wang S, Liu X (2017) Integrated train timetabling and rolling stock scheduling model based on time-dependent demand for urban rail transit. Comput Aided Civil Infrastruct Eng 32(10):856-873 